\title{
Effect Of Community Participation On Project Sustainability: A Case Of Kirehe Community-Based Watershed Management Project (KWAMP)
}

\author{
Daniel Kayijuka \\ MBA, Mount Kenya University Rwanda \\ DOI: 10.29322/IJSRP.11.08.2021.p11681 \\ http://dx.doi.org/10.29322/IJSRP.11.08.2021.p11681
}

\begin{abstract}
Sustainability is the motive of any development project layout, when not attained all the energy used seems like wasted. The outcomes of a project depend really on the commitment of the participants of the project. The overall objective of this research was to identify the relationship between beneficiary participation and project sustainability in the Community-based Watershed Management in Kirehe. This study aimed at searching about the project targeted community participation in the planning, implementation of the KWAMP looking and aiming at finding if this project was or will be sustainable. The significance of this study is based on generating knowledge regarding the participation commitment of the targeted community based on the findings that will assist to determine the best relationship between the donor communities and the beneficiaries, which can ensure sustainability of the projects. This research was conducted in Kirehe district with the community benefiting from Cyunuzi and Sagatare watershed irrigation scheme. The researcher used the Cochran formula to determine 96 beneficiaries from the community as sample size and was selected randomly from KWAMP beneficiaries to respond to the questionnaire and use the purposive method for the project implementers to provide data through guided interview. On the basis of SPSS with descriptive statistic model displaying mean and standard deviation, the researcher processed and analyzed primary data collected through a questionnaire.
\end{abstract}

Index Terms- Community Participation, Development project, Project sustainability, community and sustainability

\section{INTRODUCTION}

Community participation is a very popular paradigm for empowering people to not only be beneficiaries, but also agents of development in their projects. This is the way forward to successful and self-sustainable projects (Mikkelsen, 2010). It is important that projects for development, especially those involved into the improvement of remote communities, continue to produce the benefits wished for than expected economic life as it is called "project sustainability." (Aga et al., 2018).

Local community participation is taken as a solution to project sustainability in Africa. Community participation is a very important approach adopted in development. These approaches on participatory drives the projects to be more efficient and effective adding to project sustainability (McGee, 2002). Community participation is the center to project for development like a way to pursue equity and sustainability, especially for the vulnerable (Rifkin and Kangere 2003). McIvor (2000) claims that participation of the community is of quality when people express their part in the project conception and receive this as their own effort.

In Africa, as Gauge (2013) stated that when more responsibility is taken over by the community than public legal agencies attempting for consumer preferences evaluations through meetings and surveys, this generally result into a successful community participation. Projects need to include particular components to face Community participation in order to work. The recruitment of beneficiaries can help in the designing, implementing, maintaining, supervising, and evaluating the project, of course considering time, effort and money to be spent in the right way. More emphasis spent to the local committees' evolution and guiding governance structures to oversee adequately the participation of the community.

Rwanda through MINECOFIN and IFAD are partnering on the Kirehe Watershed Management project, which is an agricultural investment project implemented by MINIGRI that was established in April 2009. The main objective of this project is to develop sustainable small scale commercial agriculture in Kirehe district. It provides performance and continuance of accessible irrigation resources to a large portion of the active poor and farmers with no big lands in the district, to minimize dependence on increasingly erratic rains and allowing a shift to higher value crops to meet the market's demand (MINECOFIN, 2013). Thus, the research was carried out aiming to identify the connection between targeted farmers here called the community, their participation and the sustainability of KWAMP in Kirehe District.

\section{RESEARCH ELABORATION}

Participation of a community in project development leads to building capacity that equips the community for efficiency and effectiveness on the journey to Identify, implement, monitor and evaluate the projects for development (Davids et al., 2009). The people in any given locality should be allowed to determine for 
themselves, on their own initiative, what are the things that they feel the need most. The argument very populist in its orientation is that the community knows what they want. The people to be affected by them must be involved in their identification (formulation) and all phases of project life cycle.

To describe Project sustainability, three things come to mind; the community, the results of the project and the external assistance (Luvenga, Kirui, Oino and Towett, 2015). A project is considered sustainable when the beneficiary community is able on its own to continue to gain benefited results that are answering the existing problem without the assistance of outside development partners. The success of community based projects requires diverse components of sustainability to be looked upon at every stage of the project's lifecycle. It becomes importantly true where outside contribution is withdrawn after project closure, being the case of many development projects, (Ostrom, 2010).

Narayan (2008) conducted a study entitled "Impact of participation of the community on the success of community based projects "The researcher studied 121 rural water supply projects in 48 countries. The data for this study were collected from project evaluation reports, and a multivariate regression model was used to attempt to understand the effects of beneficiary participation on overall project effectiveness. In this study, participation was scored on a one to seven point scale, with a score of one indicating no participation, and a score of seven indicating high levels of participation. From the report, it is not clear what each of these levels captures. The study also looked at when participation occurred in the project cycle during the planning, construction or operation and maintenance stage. Using factor analysis, the statisticians determined that 'overall beneficiary participation' could be used as the main measure of participation. A measure of 'overall project effectiveness' was also generated using factor analysis on 20 performance outcomes. This study found beneficiary participation to be a significant indicator of overall project success; however, there are several problems with this study. First, each project had a different type of participation, ranging from when participation occurred to how participation occurred and who participated (Narayan, 2008).

Munyui (2015) researched on "Factors influencing sustainability of community water projects: a case of Kitui West Sub-County, Kitui County." The aim of the research was to investigate the factors influencing sustainability of community water projects in Kitui West Sub-County in order to make appropriate recommendations for enhancing sustainability of community water projects. The study used descriptive survey design. Data was collected using closed ended questionnaires, interviews and Focused Group Discussion (FGD). The collected data was analyzed and presented using descriptive statistics in form of

\section{RESEARCH FINDINGS}

This portion of the study represents the summary of major findings regarding three objectives that guided this study. The beneficiaries of KWAMP project asserted that they were involved in project planning, project implementation and project management after implementation of exit strategy. The extent to which adjectives frequency tables and Multiple Regression Analysis to establish the relationship between the variables. The study established that sustainability of community water projects in Kitui West SubCounty was being influenced though differently by community participation, technology, management and financial factors.

Mochiemo (2014) did a study on factors influencing sustainability of water projects in slum areas of Nairobi County: a case of Maji ni Maisha water project. The aim of the research was to investigate the factors affecting sustainability of water projects in Kenya with particular reference to Maji ni Maisha water project. The study used descriptive research design in collecting data for the study because it usually provides rich detail about the project. The data for the study was collected using the questionnaires. Quantitative data was analyzed using correlation and regression with the aid of Statistical Package for Social Sciences (SPSS17.0).The study established that water projects sustainability was influenced by financing, governance, community participation and monitoring and evaluation to high levels as project implementation and management require sufficient funding drawn from varying financial sources so as to ensure efficiency and timely procurement and maintenance of required skills, equipment and facilities. Governance is of importance in project management and performance as it provides a framework for project accountabilities and responsibilities.

The study used Simple random sampling technique to select the beneficiaries of the project who participated in this study and purposive sampling to select project implementers that could comprehend effectively with interview guide. As asserted by Levine (2001), simple random sampling technique is a design in which the cases that will make up the sample are chosen in a single process of selection from the sampling frame that covers the entire target population. In this regard each element has an equal chance of being chosen. Thus, the sample of this research was 96 respondents and two staff members. Convenience sample normally allows the research to gain data related to this research, avoiding difficulty of a randomized sample usage.

This research collected data on KWAMP, and used forms asking with opened and closed questions by the use of an administered questionnaire. The sample size was 96 beneficiaries of the project. The collected and selected data were recorded into computer software called SPSS to be analysed. The collection form clearly focused on the point of interests. In order to construct the theoretical part, a number of books and online resources were consulted and referred to. With the use of data questionnaire, data were extracted from KWAMP project beneficiaries.

were achieved are expressed by statistical data (mean and standard deviation).

\section{II1.1. Findings pertaining community participation during project phases}


Many respondents had been invited in the meeting of the project mean $=3.4375$, they involved in the planning of the project mean $=3.2998$, they strongly asserted that KWAMP project was needed mean $=4.1562$, the project implementers had the provided the information on the duration and objectives of the project mean $=4.1562$.Thus, on the basis of positive results(high mean with low standard deviation) presented in table the results presented in the table above prove that the beneficiaries involved in planning phase of the project as they were invited in projects meeting during planning phase, they were informed about the duration and objective of the project.

\section{III.2. Findings pertaining exit strategy application to project sustainability}

The respondents asserted that KWAMP project had sponsors, great mean $=4.2812$, they also asserted that the leaders of the project kept up coordinating and leading the project activities mean $=4$. 3542. They strongly asserted that they participated in the project implementation with a great mean of 3.6771 and they acquired the ability to respond to new challenges $($ mean $=3.8229$, standard deviation $=0.56185$ ) as the participation in KWAMP project implementation enhance their skills. The respondents strongly asserted that exit strategy was implemented effectively mean $=3.1771$, the project kept up running mean=2.9543, after the exit, the project was managed by some of the community members mean $=2.9583$

\section{III.3. Findings pertaining contribution on social well being}

They strongly agreed that KWAMP project contributed to growth of agricultural production in the region with a great mean $=3.0157$, and contributed considerably to poverty reduction mean $=3.4056$.the respondents asserted that after exit strategy, the community managed the project effectively mean $=4.1771$ with low standard deviation 0.73977 , they strongly agreed that the effective management of the project depends on the involvement of the projects in overall cycle of the project mean $=4.2908$ with $s t d v=0.97850$. The respondents asserted that there is a strong relationship between community involvement and project sustainability. Mean=4.1875 with standard deviation 0. 63764. It is seen that the variables are correlated at 0.01 level 2-tailled with a coefficient of 0.761 . Where the $P$ value on both variable is 0 . 000. From the table, the researcher found out that there is a strong relationship between community participation and the sustainability found effective of KWAMP project.

\section{Conclusion}

The study revealed that the beneficiaries involved in the planning of the project, they strongly asserted that KWAMP project was needed mean, the project implementers had the provided the information on the duration and objectives of the project. Thus the beneficiaries involved in planning phase of the project as they were invited in projects meeting during planning phase, they were informed about the duration and objective of the project. The respondents asserted that KWAMP project had sponsors, they also asserted that the leaders of the project kept up coordinating and leading the project activities. They strongly asserted that they participated in the project implementation with a great mean of 3.6771 and they acquired the ability to respond to new challenges as the participation in KWAMP project implementation enhance their skills.

The results regarding exit strategy and sustainability of the project reveal that applying phase a sponsor transferred program activities requiring continued inputs to the community. Regarding the application of phase over, mean $=2.7542$. The respondents strongly asserted that exit strategy was implemented effectively mean $=3.1771$, they strongly agreed that the effective management of the project depends on the involvement of the projects in overall cycle of the project mean $=4.2908$ with $s t d v=0$. 97850. The respondents asserted that there is a strong relationship between community involvement and project sustainability. Mean $=4.1875$ with standard deviation 0.63764 . It is seen that the variables are correlated at 0.01 level 2-tailled with a coefficient of 0.761 . Where the $\mathrm{P}$ value on both variable is 0.000 . From the table, the researcher found out that there is a strong relationship between community participation and the sustainability found effective of KWAMP project.

\section{REFERENCES}

Aga, D. A., Noorderhaven, N., \& Vallejo, B. (2018). Project beneficiary participation and behavioral intentions promoting project sustainability: The mediating role of psychological ownership. Development Policy Review, 36(5), 527-546.

Davids, I. T. (2009). Participatory development in South Africa: A Development Management Perspective. Pretoria: Van Schaik.

Luvega, C., Kirui, K., Oino, P., and Towett, G. (2015). The dilemma in sustainability of Community based projects in Kenya. Global Journal of advanced research Vol-2, Issue-4 PP. 757-768

McIvor, C. (2000). Community Participation in Water Management: Experiences from Zimbabwe, Development and Cooperation, www.inwent.org accessed 23 April 2011.

Mikkelsen Li, H. \& Turner, R. (2007) Managing the environment,.Turner (ed.), Gower Handbook of Project Management 4th ed., Gower Publishing, Aldershot, UK.

Munyui, K. (2015). Factors Influencing Sustainability Of Community Water Projects: A Case

Of Kitui West Sub-County, Kitui County. Unpublished MA Project, University of Nairobi.

Ostrom, T.K. (2010). Considering sustainability factors in the development Project lifecycle: A framework for increasing successful adoption of improved Stoves. 